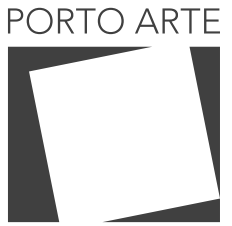

Revista de Artes Visuais

v. $25 \mathrm{n} .43$

Jan/jun 2020

e-ISSN: 2179-8001

\title{
The Visitors, de Ragnar Kjartansson
}

The Visitors, by Ragnar Kjartansson

\section{Carlos Donaduzzi}

Universidade Federal do Rio Grande do Sul, Brasil ORCID: https://orcid.org/0000-0003-4044-8259

\section{Resumo}

Essa resenha é um relato sobre a experiência de visitação de The Visitors, de Ragnar Kjartansson, uma instalação audiovisual apresentada no Institute of Conteporary Art - ICA, em Boston, nos Estados Unidos no ano de 2019. As percepções diante das imagens e sons são exploradas relacionando os efeitos proporcionados às reações dos visitantes na exposição.

Palavras-chave

Ragnar Kjartansson. Instalação Audiovisual. Arte Contemporânea. ICA - Boston. Experiência.

\section{Abstract}

This review is a report of the visitation experience of The Visitors by Ragnar Kjartansson, a video projection presented at the Institute of Contemporary Art - ICA in Boston, United States in the year 2019. Perceptions of images and sounds are explored relating to the effects provided on the reactions of the visitors to the exhibition.

Keywords

Ragnar Kjartansson. Video Projection. Contemporary art. ICA - Boston. Experience. 


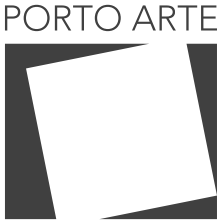

Revista de Artes Visuais

v.25 n.43 Jan/jun 2020 e-ISSN: 2179-8001
Figura 1: The Visitors, 2019

Ragnar Kjartansson. Vídeo instalação, 9 telas, 64 minutos Vista da exposição. Disponíve

em: https://www.icaboston org/video/ragnar-kjartanssonvisitors-vinyl-factory
A porta do elevador abre-se e após poucos passos, logo na entrada da galeria principal, de paredes brancas e muito iluminadas do Institute of Contemporary Art ICA, em Boston, nos Estados Unidos, encontra-se uma abertura para uma sala escura onde um texto com letras pequenas convidava o visitante para se aproximar. "Um retrato sentimental sobre amizade, amor e perda..." (De BLOIS, 2019, tradução nossa)1 é a primeira frase que se pode ler e talvez o grande resumo da instalação audiovisual The Visitors (Figura 1), obra original de 2012 do artista islandês Ragnar Kjartansson, com montagem atualizada em 2019 e que se encontra ao atravessar por essa passagem.

As pessoas entram e saem da sala onde está a obra de Kjartansson caminhando lentamente por através de um corredor que separa o texto curatorial das imagens. Após a passagem da claridade para a escuridão, entra-se em uma sala retangular totalmente negra, do chão ao teto, onde em cada uma das quatro paredes vídeos são projetados, somando-se a outros dois vídeos que dividem os lados de uma parede ao centro da sala, criando um percurso circular que à primeira vista parece ser a intenção da obra.

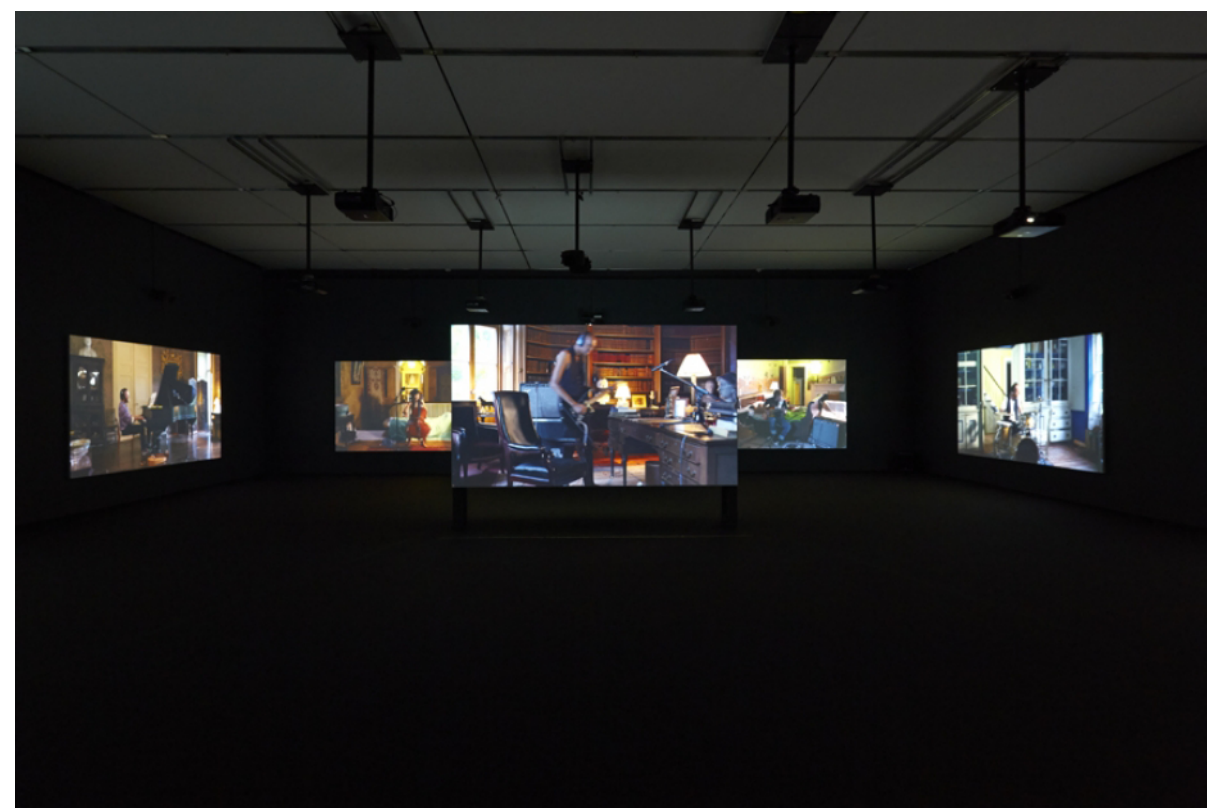

Os avisos de proibido filmar e de não usar flash ao fotografar estão em destaque no rodapé do texto curatorial e são mensagens rapidamente compreendidas, pois neles estão implícitos um convite a intimidade, a do artista, a dos demais visitantes e a nossa própria. Imagens em movimento e áudio criam uma atmosfera que faz com que todos no espaço diminuam a intensidade dos passos, fazendo com que os sons das inspirações e expirações de cada pessoa presente na sala se some aos ruídos emitidos pela obra.

1- No original: "A sentimental portrayal of friendship, love, and loss..." (De BLOIS, 2019) 


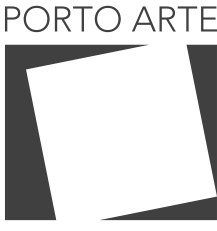

Revista de Artes Visuais

$\vee 25 n .43$

Jan/jun 2020 e-ISSN: 2179-8001

Em The Visitors, entre os visitantes que caminhavam diante as projeções, os que permanecem parados em pé e os que se sentam ao chão, estão as imagens dos músicos, cada um ocupando um diferente cômodo de uma antiga casa e projetados separadamente nas paredes da galeria. Todos eles, cada qual com seu instrumento, cantam e tocam sincronizados a mesma canção. Os versos que podem ser escutados, que soam como temas entre o gospel e o folclórico, são trechos do poema Feminine Ways, escrito pela artista Ásdís Sif Gunnarsdóttir, que se combinam através de diferentes vozes, masculinas e femininas, construindo um lamento denso e coletivo (FRIELING, 2016).

Do banheiro desta casa, o som do cantar do músico, o próprio Ragnar Kjartansson, confunde-se com os estalos da água nas bordas da banheira em que ele se encontra imerso, e assim, tornam-se também notas da composição. 0 ruído do vento invade um dos quartos e mostra a natureza compondo com a musicista que dedilha o seu violão diante de uma janela. 0 baterista, longe e diante da mesa da cozinha faz o seu som espalhar-se por todos os cômodos. Do piano na sala de estar que conduz a peça musical, ao violinista na sala de jantar, passando pelos quartos, corredores e pela varanda que conectava o interior com o exterior desse espaço de convívio e colaboração, a casa faz parte de toda música.

A melodia suave e lírica que emerge de cada uma das cenas se une na totalidade das projeções em grande formato e nos coloca, os visitantes, como plateia, testemunhas e talvez até como participantes desse momento de comunhão e amizade. Aos poucos, os músicos passam a deslocar-se, saindo dos cômodos onde estão. Logo, diante do vídeo da sala de estar onde está o pianista, esses mesmos personagens começam a surgir por diferentes ângulos do enquadramento e todos juntos, agora fisicamente próximos, cantam a canção que sussurravam à distância. É possível sentir-se dentro da casa. 0 áudio do ambiente expositivo permite escutar com perfeição os ruídos que surgem na obra, o estouro da garrafa de champanhe, as risadas e os passos que fazem as madeiras do piso estalarem.

Todos os outros cômodos tornam-se vazios e silenciosos, mas ainda podemos vê-los e pode-se sentir os vestígios da música que parece permanecer entre as paredes. Assim como esses ambientes, os lugares que esses vídeos ocupam na galeria tornam-se vazios de espectadores. Nesse momento, todos os visitantes, os da exposição, talvez até mesmo sem perceber, já não estão mais em pé e parados, caminhando ou sentados diante de projeções distintas. Todos estão, assim como os músicos, reunidos diante do mesmo enquadramento.

Pouco a pouco, os músicos deslocam-se para fora da casa e consequentemente surgem na tela que transmite o exterior desse local. E, mais uma vez, os visitantes seguem seus passos e também se deslocam. Inicia-se uma caminhada, no vídeo e na galeria. A música torna-se cada vez mais suave, lenta e distante. Já próximo ao final, após os 64 minutos de composição, com os músicos ao longe em uma paisagem verde durante o pôr de sol, percebe-se que todos aqueles desconhecidos, visitantes que inicialmente estavam espalhados pela sala diante de diferentes projeções, estão há alguns minutos reunidos. A obra aproxima desconhecidos e por um pequeno momento todos parecem ter compartilhado os mesmos sentimentos, antes de novamente se dispersarem com o final do vídeo e o sair da escuridão. 


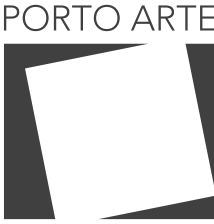

Revista de Artes Visuais

v.25 n.43 Jan/jun 2020 e-ISSN: 2179-8001
Figura 2: Death Is Elsewhere 2019, Ragnar Kjartansson. Vídeo instalação, 7 telas, 77 minutos. Vista da entrada da instalação com o aviso de que não permitia a captura de imagens. Disponível em: https://vimeopro $\mathrm{com} /$ tomastomasson/art/ video/379205531

\section{Além da narrativa}

A poética de Kjartansson é sobre convites e aproximações. Death Is Elsewhere, de 2019 (Figura 2) é um dos trabalhos mais recentes do artista. Apresentado no The Metropolitan Museum of Art em Nova York nesse mesmo ano, mais uma vez estamos diante de uma instalação audiovisual de múltiplas telas. Com um tom romântico que se assemelha a The Visitors, dois músicos cantam e tocam uma canção enquanto caminham lentamente por uma paisagem fria e desabitada.

Com menor intensidade se comparada a primeira obra e sobretudo pela expografia que dispõe as sete telas que compõem a instalação em uma galeria aberta do The $M E T$, o visitante não se vê imerso na atmosfera proposta, principalmente pela movimentação e ruídos que povoam toda a extensão do museu. Ainda assim, Death Is Elsewhere, inspirada segundo o próprio artista2 nas pinturas de ciclorama, é uma obra marcante pela sua simplicidade. Editada em loop, o movimento circular é mantido também pelos personagens que caminham constantemente e alteram a vegetação sob os seus pés pelo excesso de passos.

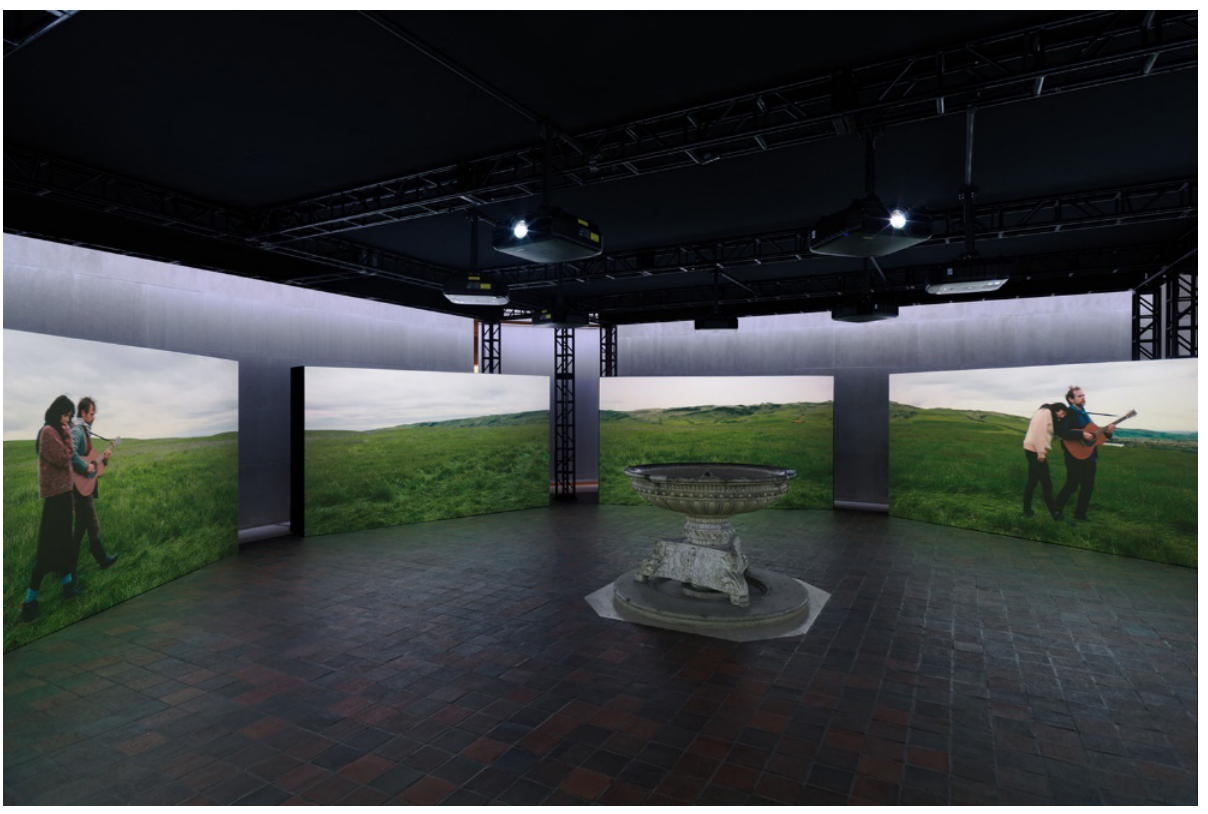

Da mesma maneira, alguns espectadores da obra caminham em círculos pelo espaço expositivo, percorrendo o mesmo trajeto dos personagens. Ainda que o chão de pedra do museu seja tão distinto do capim verde que é possível observar balançando com o vento em cada um dos vídeos da instalação, muitas pessoas parecem sentir-se

\footnotetext{
2- KJARTANSSON, Ragnar. Ragnar Kjartansson on Death Is Elsewhere. The MET, Nova York, 12 ago. 2019 Disponível em: https://www.metmuseum.org/blogs/now-at-the-met/2019/ragnar-kjartansson-death-is-elsewhere. Acesso em: 20 ago. 2019
} 


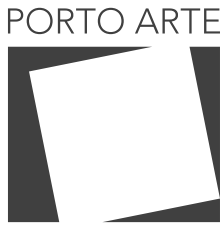

Revista de Artes Visuais

v. 25 ก. 43

Jan/jun 2020 e-ISSN: 2179-8001

como parte daquele momento projetado nas telas. Outras permanecem sentadas nos bancos posicionados ao centro da obra, mas sempre atentas as imagens que se alternam entre a presença e a ausência dos artistas nos enquadramentos.

"Eu nunca procuro fazer filmes com narrativas. Eu faço filmes que não têm histórias, porém, há uma ideia de história em torno disso."3, conta Kjartansson (2019, tradução nossa). Essas possíveis histórias, como menciona o próprio artista, talvez possua relação com a ideia de que seus trabalhos "são sempre sobre sentimentos."4 (KJARTANSSON, 2013). E, são desses possíveis sentimentos que podem surgir dessas conexões entre obra-público que após poucos segundos de observações, muitos dos espectadores tornam-se ativos e integrantes dos rituais propostos pelas suas instalações audiovisuais.

0 artista, sem a intenção de forçar o efeito, "quer apenas produzir uma forma de consciência, uma intensidade de sentimento, uma energia para a ação." (RANCIÈRE, 2014, p. 18). Por sua vez, esta ação não é controlada ou indicada de maneira explícita, por mais que pareça fazer parte da composição e inscrita no projeto da obra. 0 seu efeito depende do momento, da reverberação da obra e da sua interpretação pelo público. E, em diferentes níveis, essa condição se manifesta nas instalações mencionadas de Kjartansson.

\section{Apontamentos finais}

The Visitors foi gravada em tempo real durante um entardecer de verão em uma antiga casa de fazenda. A atmosfera do local e o pôr do sol fizeram com que os versos cantados repetidas vezes pelos músicos tornassem a performance hipnótica5. Em uma entrevista6, Kjartansson menciona que o projeto e execução do que ele chama de filme, foi constituído em um momento pessoal onde o seu sentimento era o de "derrota". Assim, os ciclos crescentes e decrescentes da vida se fazem também presentes nas entonações das vozes e na intensidade de como os instrumentos são tocados.

Entre sussurros, notas quase inaudíveis e um final catártico, estão momentos de improviso, extrema melancolia e desafogo. A casa, lida como cenário, músico, personagem e espectadora, conecta os sons distantes que se sobrepõem ao longo de toda duração do filme. Desse modo, com todas as possibilidades de telas, o espetador é livre para percorrer o espaço expositivo e constituir a sua própria versão de The Visitors.'

\footnotetext{
3- No original: "I've never wanted to make a narrative film. I make films that have no stories, but there's the idea of a story around it." (KJARTANSSON, 2019). 4- No original: "They're always about a feeling..." (KJARTANSSON, 2013).

5- NEEDHAM, Alex. Interview: The maddest house party ever - Ragnar Kjartansson on making The Visitors. The Guardian, Londres - UK, 17 set. 2019. Disponível em: https://www.theguardian.com/artanddesign/2019/sep/17/ragnar-kjartansson-the-visitors-best-art-work-21st-century. Acesso em: 1 out. 2019. 6- NEEDHAM, Alex. Interview: The maddest house party ever - Ragnar Kiartansson on making The Visitors. The Guardian, Londres - UK, 17 set. 2019. Disponível em: https://www.theguardian.com/artanddesign/2019/sep/17/ragnar-kjartansson-the-visitors-best-art-work-21st-century. Acesso em: 1 out. 2019.
} 


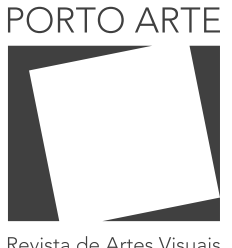

Revista de Artes Visuais

\section{Informações:}

Exposição: Ragnar Kjartansson: The Visitors

Curadoria: Jeffrey De Blois

Local: Institute of Contemporary Art - ICA, Boston - MA, Estados Unidos

Período: de 13 de fevereiro a 28 de julho de 2019

\section{REFERÊNCIAS}

DE BLOIS, Jeffrey. Ragnar Kjartansson: The Visitors. Institute of Contemporary Art ICA, Boston, 2019. Disponível em: https://www.icaboston.org/exhibitions/ragnar-kjartansson-visitors-1. Acesso em: 30 maio 2019.

KJARTANSSON, Ragnar. Ragnar Kjartansson on Death Is Elsewhere. The MET, Nova York, 12 ago. 2019. Disponível em: https://www.metmuseum.org/blogs/now-at-the-met/2019/ragnar-kjartansson-death-is-elsewhere. Acesso em: 20 ago. 2019.

NEEDHAM, Alex. Interview: The maddest house party ever - Ragnar Kjartansson on making The Visitors. The Guardian, Londres, 17 set. 2019. Disponível em: https:// www.theguardian.com/artanddesign/2019/sep/17/ragnar-kjartansson-thevisitors-best-art-work-21st-century. Acesso em: 1 out. 2019.

RANCIÈRE, Jacques. $O$ espectador emancipado. São Paulo: Martins Fontes, 2014.

RUDOLF, Frieling. Ragnar Kjartansson: The Visitors. SFMoMA - San Francisco Museum of Modern Art, San Francisco, 2016. Disponível em: https://www.sfmoma.org/ $\mathrm{read} / \mathrm{ragnar-kjartansson/.} \mathrm{Acesso} \mathrm{em:} 30$ maio 2019.

SHEETS, Hilarie. Never Tiring of Repeating Himself. New York Times, Nova York, 2 jan. 2013. Disponível em: https://www.nytimes.com/2013/01/06/arts/design/the-visitors-by-ragnar-kjartansson.html. Acesso em: 10 jun. 2019. 


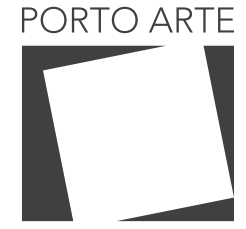

Revista de Artes Visuais

v. $25 \mathrm{n} .43$ Jan/jun 2020 e-ISSN: 2179-8001

\section{Carlos Donaduzzi}

Fotógrafo - Artista Visual. Doutorando em Artes Visuais pelo PPGAV/UFRGS. Prática artística em fotografia, atualmente buscando discutir sobre o paradoxo real/virtual.

Texto recebido em: 01/07/2019

Texto aceito em: $17 / 12 / 2019$

Texto publicado em: 26/02/2020

Como citar: DONADUZZI, Carlos. The Visitors, de Ragnar Kjartansson. PORTO ARTE: Revista de Artes Visuais, Porto Alegre, RS, v. 25, n. 43, jan-jun 2020 ISSN 2179-8001. 